\title{
Impact Assessment of COVID-19 Pandemic Through Machine Learning Models
}

\author{
Fawaz Jaber Alsolami ${ }^{1}$, Abdullah Saad Al-Malaise ALGhamdi ${ }^{2}$, Asif Irshad Khan ${ }^{1, *}$, \\ Yoosef B. Abushark ${ }^{1}$, Abdulmohsen Almalawi ${ }^{1}$, Farrukh Saleem ${ }^{2}$, Alka Agrawal ${ }^{3}$, \\ Rajeev Kumar ${ }^{3,4}$ and Raees Ahmad Khan ${ }^{3}$
}

\author{
${ }^{1}$ Department of Computer Science, Faculty of Computing and Information Technology, King Abdulaziz University, \\ Jeddah, 21589, Saudi Arabia \\ ${ }^{2}$ Department of Information Systems, Faculty of Computing and Information Technology, King Abdulaziz University, \\ Jeddah, 21589, Saudi Arabia \\ ${ }^{3}$ Department of Information Technology, Babasaheb Bhimrao Ambedkar University, Lucknow, 226025, India \\ ${ }^{4}$ Department of Computer Application, Shri Ramswaroop Memorial University, Barabanki, 225003, India \\ *Corresponding Author: Asif Irshad Khan. Email: aikhan@kau.edu.sa \\ Received: 29 January 2021; Accepted: 01 March 2021
}

\begin{abstract}
Ever since its outbreak in the Wuhan city of China, COVID-19 pandemic has engulfed more than 211 countries in the world, leaving a trail of unprecedented fatalities. Even more debilitating than the infection itself, were the restrictions like lockdowns and quarantine measures taken to contain the spread of Coronavirus. Such enforced alienation affected both the mental and social condition of people significantly. Social interactions and congregations are not only integral part of work life but also form the basis of human evolvement. However, COVID-19 brought all such communication to a grinding halt. Digital interactions have failed to enthuse the fervor that one enjoys in face-to-face meets. The pandemic has shoved the entire planet into an unstable state. The main focus and aim of the proposed study is to assess the impact of the pandemic on different aspects of the society in Saudi Arabia. To achieve this objective, the study analyzes two perspectives: the early approach, and the late approach of COVID-19 and the consequent effects on different aspects of the society. We used a Machine Learning based framework for the prediction of the impact of COVID-19 on the key aspects of society. Findings of this research study indicate that financial resources were the worst affected. Several countries are facing economic upheavals due to the pandemic and COVID-19 has had a considerable impact on the lives as well as the livelihoods of people. Yet the damage is not irretrievable and the world's societies can emerge out of this setback through concerted efforts in all facets of life.
\end{abstract}

Keywords: Coronavirus; social impact; safety; COVID-19 monitoring; machine learning framework; fuzzy AHP-TOPSIS 


\section{Introduction}

The impact of COVID-19 has been devastating on the societies, communities and economies across the world. The pandemic has affected almost everyone's life today. In fact, many sociologists are already dividing the present era into two distinct timelines of the life before and the life after the pandemic. Besides the impact on the health of those who contacted the virus, the pandemic also became the vector for job losses, lack of essential resources, scarcity of foodgrains, economic setbacks, low or negligible industrial activity and output. Many experts and researchers believe that it would take considerable amount of time to restore the social and economic systems across the world to their pre-COVID-19 growth trajectory.

It has now been proven that this pandemic is the most terrifying and harmful phase that the world is going through after the Second World War [1]. On January 31, 2020 the WHO (World Health Organization) declared the outbreak of Coronavirus a pandemic and a global health emergency. Hence, it is a collective responsibility of all countries across the world to cure and tackle this health exigency [2]. Inspite of the various preventive measures being taken in this context, increasing number of corona cases are visible in various countries [3]. As an initial step, restricting travel to Corona hotspots and containing the interaction between infected and normal peoples was considered as an effective safeguard. Thereafter, the governments across the world imposed intermittent periods of lockdowns to control the transmission. However, closing all public or private places affected businesses; retarding all commercial and industrial activity in many countries. This phenomenon led to major economic tailspin, as evident by dismal GDPs registered by many countries in the wake of COVID-19. This pandemic affected both the social life as well as the mental well-being of the people [4]. Lack of interactions, social distancing norms, and curbs on social congregations of any kind led to loneliness, paranoia and feeling of angst among many. After an in-depth analysis of the impact of the outbreak, it is has been shown that COVID-19 pandemic is not only a health emergency, it also a social and a financial challenge that the world is battling with. The spread ratio and pattern of the pandemic is very similar and systematic throughout every country in world. As of January 25, 2021, approximately 100 million coronavirus (COVID-19) cases have been recorded globally. More than 210 nations and regions have been affected by the outbreak, with the United States reporting about one-fifth of all worldwide outbreaks [5]. Following Fig. 1 describes the case and death ratio in various countries which has active impact on global stage. The adverse impact of this pandemic also caused various security related concerns [6-8].

Social factors that have been severely affected due to the pandemic and the social consequences because of this have become a significant research premise today. Researchers across all domains, from the field of social science, education, medicine, management and IT are studying the repercussions of the pandemic and working on effective countermeasures to help the society and people. Pandemic crisis always create fear in common peoples' mind because such an acute health emergency affects their usual routine as well as their lifestyles. Pandemics disrupt life's natural process, and everyone has a specific experience of the diseases' outbreak. More specifically, the effect of the pandemic also varies from one region to the next in the same country. Moreover, the impact and the response to the disease can also vary depending on the age groups. Hence, Machine Learning framework was adopted by the authors in this paper for evaluating the impact of Coronavirus on different social factors in Saudi Arabia [9-12].

The rest of this manuscript has been structured as: Second section deliberates upon materials and methods adopted by the proposed research study. Third section presents the empirical analysis. The fourth section enlists the findings of the proposed study. Section 5 discusses the 
findings of this research study. Finally, the conclusion of the article has been presented in the last section.

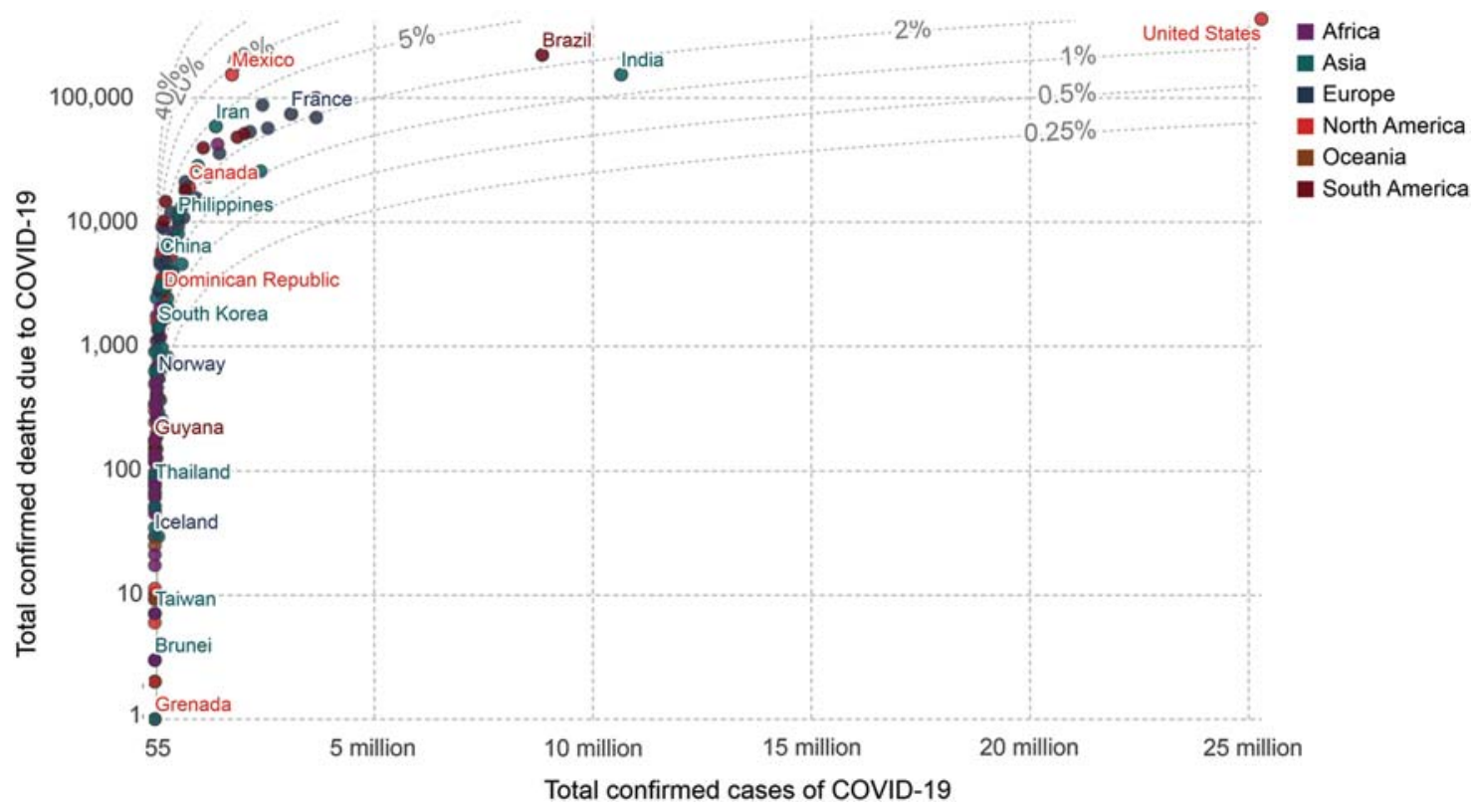

Figure 1: Total confirmed COVID-19 deaths vs. cases, January 25, 2021

\section{Materials and Methods}

\subsection{COVID-19 Pandemic in Saudi Arabia}

More than 367,276 COVID-19 cases have been confirmed and 6,366 cases have been reported as of January 252021 in Saudi Arabia [13]. The country reported its first case on 2 March 2020. The outbreak resulted in the temporary shutdown of air traffic, industries, public offices as well as public transport. The two holy mosques in Makkah (for Umrah) and Almadinah were also closed down [14,15]. The Kingdom also discontinued the export of all medical equipments and drugs and security experts to guarantee their accessibility for combating the COVID-19 disease outbreak. A large number of healthcare providers were also allocated to deal with COVID-19 exigencies in different regions of the country. The ultimate accountability in Saudi Arabia for the implementation of COVID-19 resides with the Ministry of Health $(\mathrm{MoH})$ and hospital bodies, which agree on the best way to plan and respond. A number of preventive steps were taken by the Kingdom of Saudi Arabia against COVID-19. The instant move was to create a committee of different government agencies to decide and enforce the appropriate measures targeting COVID-19 [16]. The following Fig. 2 shows the cumulative number of COVID-19 cases in Saudi Arabia on January 25, 2021.

\subsection{Criteria and Alternatives}

To conduct the evaluation process in this paper, the authors acquired literature review and questionnaires from various experts on the relevant topic and questions. Authors evaluated and conducted an in-depth review of 30 different research studies to identify the use of Machine Learning techniques for predicting or curing the Coronavirus cases. To make it more validated 
and appropriate from the industry point of view, the authors also discussed and collated the opinions from various experts related to relevant field. After interacting with 60 experts in the given domain, we selected 43 valid responses to evaluate the social attributes or factors for this pandemic situation.

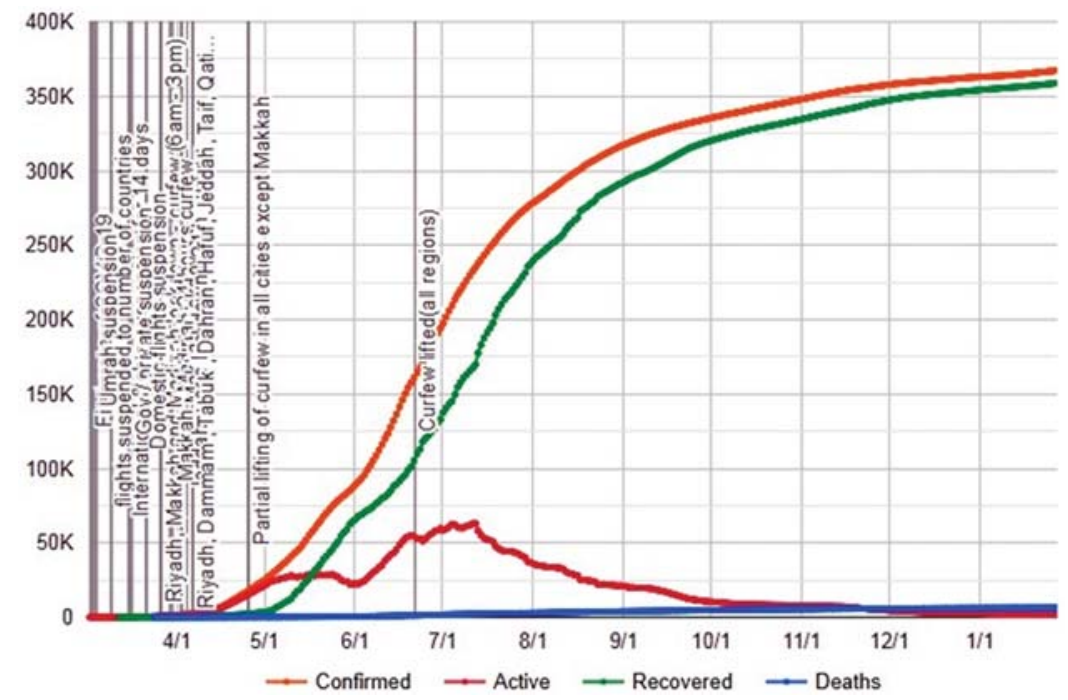

Figure 2: Cumulative total COVID-19 cases in Saudi Arabia

Table 1: COVID-19 social impact evaluation criteria

\begin{tabular}{|c|c|c|c|}
\hline Criteria & Sub-criteria & Description & Reference \\
\hline \multirow[t]{3}{*}{$\begin{array}{l}\text { Traditional } \\
\text { (CT1) }\end{array}$} & Testing (CT11) & $\begin{array}{l}\text { A proper automated testing of infected persons is } \\
\text { important process for generating the results. }\end{array}$ & [17] \\
\hline & Screening (CT12) & $\begin{array}{l}\text { It is a preventive measure which is supposed to } \\
\text { conduct for identify potential un identified threat } \\
\text { vectors of COVID-19 in country. }\end{array}$ & [10] \\
\hline & Forecasting (CT13) & $\begin{array}{l}\text { A proper automated based forecasting model helps in } \\
\text { predicting the increase or decrease in the spread of } \\
\text { the pandemic. }\end{array}$ & [11-13] \\
\hline \multirow[t]{3}{*}{$\begin{array}{l}\text { Machine } \\
\text { learning } \\
\text { (CT2) }\end{array}$} & $\begin{array}{l}\text { Drug/vaccine } \\
\text { development (CT21) }\end{array}$ & $\begin{array}{l}\text { Drug/vaccine development is a big challenge for } \\
\text { researchers and health experts all over the world. ML } \\
\text { techniques help in finding the suitable vaccine based } \\
\text { on the symptoms. }\end{array}$ & [14-16] \\
\hline & $\begin{array}{l}\text { Improve treatment } \\
\text { (CT22) }\end{array}$ & $\begin{array}{l}\text { ML is used to augment the diagnosis of patient by } \\
\text { the blood sample, X-ray and CT scan. ML based } \\
\text { techniques improve the results of radiology. }\end{array}$ & {$[14,17]$} \\
\hline & $\begin{array}{l}\text { Contact tracing } \\
\text { (CT23) }\end{array}$ & $\begin{array}{l}\text { Contact tracing is a prevention of the spread of } \\
\text { COVID-19. The disease is transferred from } \\
\text { person-to-person by droplets and saliva. Machine } \\
\text { learning is the most effective technique for tracing/ } \\
\text { detecting the infected. }\end{array}$ & {$[13,15]$} \\
\hline
\end{tabular}


The impact of COVID-19 on different social aspects in Saudi Arabia is based on two main criteria and represented as the (CTi), and is responsible for eight alternatives sites (ATi). The two main criteria are: Traditional approach (CT1), and the Machine Learning (CT2). Eight alternatives are: Education (AT1), Work (AT2), Emotional (AT3), Religion (AT4), Financial (AT5), Relationships (AT6), Psychological (AT7) and Gathering (AT8). Tab. 1 explicates all the identified criteria for evaluating the impact of pandemic on different social factors in Saudi Arabia.

\subsection{Fuzzy AHP-TOPSIS}

Fuzzy AHP-TOPSIS methodology has been used by several researchers to resolve their difficult decision-making issues. We adopted the combined approach of AHP, TOPSIS and Fuzzy to score RL adoption solutions. AHP is a multi-criteria decision-making (MCDM) process used to decide the comparative significance of the evaluation criteria by pair-wise comparisons. The stated method is also apt for recognizing the theoretical and practical dependent variable/characteristics; fuzzy advocates for uncertainty as well as fuzziness in the complex decision-making process. The Fuzzy TOPSIS approach can be applied on the chosen criteria for assessing several specified alternatives. This has been utilized in several applications in the real time scenarios. The following subsections describe these techniques in detail.

\subsubsection{Fuzzy AHP}

It is an approach that was first established and discussed by Saaty [18]. A better comparison of the decision-making approach must handle ambiguity or uncertainty because fluidity and inaccuracy are prominent features in many decision-making issues. Although decision-makers also provide unpredictable responses instead of accurate estimates, it may not be reasonable to convert quantifiable perceptions into point measurements. Traditional AHP that requires arbitrary values to be selected in pair-wise comparisons may not be appropriate, and ambiguity should be regarded in some or all comparative values [19]. Although the fuzzy linguistic technique can consider decision-makers' enthusiasm/idealism evaluation mindset, linguistic attributes, whose membership features are typically defined by triangular fuzzy numbers (TFNs), are suggested for determining preferential ratings rather than traditional numerical correlation methods [20]. Hence, the fuzzyAHP is much more efficient and suitable in real practice than traditional AHP in which there is an unpredictable pair-wise comparisons situation [21].

Researchers transform this further into precise numbers and TFN for getting linguistic values. This study uses the TFN and range of TFN lies between zero and one. Such an acknowledgment is explained by the numerical adaptability and capability of triangular fuzzy involvement functions for interacting with fuzzy data [22]. Therefore, linguistic variables are classified as incredibly significant, weakly significant, etc., and the exact numbers are classified as $1,2,3, \ldots, 9$. Nevertheless, if its involvement functions are defined in Eqs. (1)-(2), it produces the TFN value:

$\mu_{\mathrm{a}}(\mathrm{x})=\mathrm{F} \rightarrow[0,1]$

$\mu_{a}(x)= \begin{cases}\frac{x}{m i-l}-\frac{l}{m i-l} & x \in[l, m i] \\ \frac{x}{m i-u}-\frac{u}{m i-u} & x \in[m i, u] \\ 0 & \text { Otherwise }\end{cases}$ 
where, 1 , mi, and $\mathrm{u}$ are indicated subsequently in the TFN to display about limits as minimum, medium and maximum. The following Fig. 3 represents the TFN.

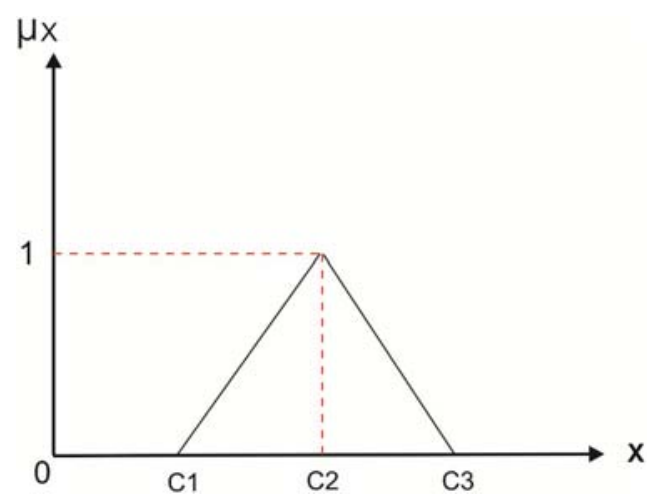

Figure 3: Triangular fuzzy numbers

Triangular fuzzy numbers can be inferred as various limit parameters. Domain Experts suggest their opinions as per the scale provided in Tab. 2 for the variables that affect the values in a mathematical manner.

Table 2: TFN scale

\begin{tabular}{lll}
\hline Numeric value & Fuzzy triangle number & \\
\hline 1 & (Equally weighty) & {$[1,1,1]$} \\
3 & (Weakly weighty) & {$[2,3,4]$} \\
5 & (Fairly weighty) & {$[4,5,6]$} \\
7 & (Strongly weighty) & {$[6,7,8]$} \\
9 & (Absolutely weighty) & {$[9,9,9]$} \\
2 & (Intermittent values between two & {$[1,2,3]$} \\
4 & adjacent scales) & {$[3,4,5]$} \\
6 & & {$[5,6,7]$} \\
8 & & {$[7,8,9]$} \\
\hline
\end{tabular}

To convert the opinions given by the experts about factors into numerical values, the Eqs. (3)(6) are used $[22,23]$. Where $1, \mathrm{mi}$ and $\mathrm{u}$ represent the same limit values, but this time we need to calculate them for each factor.

$\eta_{i j}=\left(l_{i j}, m i_{i j}, u_{i j}\right)$

where,

$l_{i j} \leq m i_{i j} \leq u_{i j}$

$l_{i j}=\min \left(J_{i j d}\right)$

$m i_{i j}=\left(J_{i j 1}, J_{i j 2}, J_{i j 3}\right)^{\frac{1}{x}}$ 
and,

$u_{i j}=\max \left(J_{i j d}\right)$

In between the above formulas, $J_{i j k}$ portrays the relation based consequence of the values between two elements given by the expert $\mathrm{d}$, though $\mathrm{I}$ and $\mathrm{j}$ designate a pair of factors that the experts regulate. $\eta_{i j}$ is considered with respect to the arithmetical mean of specialized expert's interpretations in a restricted distinction. In the context of $\mathrm{M} 1 \& \mathrm{M} 2, \mathrm{M} 1=(11, \mathrm{mi1}, \mathrm{u} 1), \mathrm{M} 2=$ (12, mi2, u2), the functioning rules regulating them are as shown in Eqs. (7)-(9):

$\left(l_{1}, m i_{1}, u_{1}\right)+\left(l_{2}, m i_{2}, u_{2}\right)=\left(l_{1}+l_{2}, m i_{1}+m i_{2}, u_{2}+u_{2}\right)$

$\left(l_{1}, m i_{1}, u_{1}\right) \times\left(l_{2}, m i_{2}, u_{2}\right)=\left(l_{1} \times l_{2}, m i_{1} \times m i_{2}, u_{1} \times u_{2}\right)$

$\left(l_{1}, m i_{1}, u_{1}\right)^{-1}=\left(\frac{1}{u_{1}}, \frac{1}{m i_{1}}, \frac{1}{l_{1}}\right)$

With the help of Eq. (10), the experts transform the values of TFN into the form of matrix.

$\widetilde{A^{d}}=\left[\begin{array}{ccc}\tilde{k}_{11}^{d} & \tilde{k}_{12}^{d} \ldots & \tilde{k}_{1 n}^{d} \\ \tilde{k}_{21}^{d} & \tilde{k}_{22}^{d} \ldots & \tilde{k}_{2 n}^{d} \\ \ldots & \ldots & \ldots \\ \tilde{k}_{n 1}^{d} & \tilde{k}_{n 2}^{d} \ldots & \tilde{k}_{n n}^{d}\end{array}\right]$

where $\widetilde{k_{i j}^{k}}$ denotes the privilege of the dth domain expert for the ith criteria over most of the jth criteria. In case of more than one domain expert, the average of the priorities of each domain expert is measured by using Eq. (11).

$\tilde{k}_{i j}=\sum_{d=1}^{d} \tilde{k}_{i j}^{d}$

Additionally, now it's time to calculate the matrix value for every selected factor in tree like structure. To make it possible, Eq. (12) is used.

$\tilde{A}=\left\lfloor\begin{array}{ccc}\widetilde{k_{11}} & \ldots & \widetilde{k_{1 n}} \\ \ldots & \ddots & \ldots \\ \widetilde{k_{n 1}} & \ldots & \tilde{k}_{n n}\end{array}\right\rfloor$

Afterwards, we have used the geometric mean calculation approach as given in Eq. (13) to evaluate it for every specific factor.

$\tilde{p}_{i}=\left(\prod_{j=1}^{n} \tilde{k}_{i j}\right)^{\frac{1}{n}}, \quad i=1,2,3 \ldots, \mathrm{n}$ 
The subsequent phase is to decide the factor's fuzzy weight through Eq. (14).

$\tilde{w}_{i}=\tilde{p}_{i} \otimes\left(\tilde{p}_{1} \oplus \tilde{p}_{2} \oplus \tilde{p}_{3} \ldots \oplus \tilde{p}_{n}\right)^{-1}$

Consequently, by the Eqs. (15)-(16), the mean and standardized weights have been estimated.

$M_{i}=\frac{\tilde{w}_{1} \oplus \tilde{w}_{2} \ldots \oplus \tilde{w}_{n}}{n}$

$N r_{i}=\frac{M_{i}}{M_{1} \oplus M_{2} \oplus \ldots \oplus M_{n}}$

Thereafter, by applying Eq. (17), the Center of Area (COA) technique is implemented to assess the significance of factors numerically.

$B N P w D 1=\frac{[(u w 1-l w 1)+(m i w 1-l w 1)]}{3}+l w 1$

\subsubsection{Fuzzy TOPSIS}

The method is described in Chen et al. [24] study, and can be seen in Hwang et al. [25] work as well. TOPSIS represents a different method for identifying alternatives from a finite particular solution. As a working process of the methodology, every project which is adopted as alternative should have the some degree of closeness from $+v e$ and -ve standards. This approach defines $\mathrm{m}$ alternatives as a MCDM problem, by implementing classical mathematical computational techniques. This method relates fuzzy numbers in integration with the actual-world fuzzy environment to characterize the relative significance of the criterion, rather than the actual figures. Besides, the Fuzzy AHP-TOPSIS technique is mainly suited for finding collective decision-making alternatives in fuzzy environments.

As an initial step, experts need to select values for the COVID-19 social impact assessment factor. This research study uses FAHP technique to decide fuzzy preference weights by the Eqs. (1)-(16). Additionally, we constructed the fuzzy based decision matrix (Eq. (18)) and selected the suitable social factors for experimenting results that are referred to as alternatives in this study and portrayed by the authors in the Tab. 3 .



where, $\tilde{x}_{i j}=\frac{1}{D}\left(\tilde{x}_{i j}^{1} \cdots \oplus \tilde{x}_{i j}^{d} \oplus \cdots \tilde{x}_{i j}^{D}\right)$, and $\tilde{x}_{i j}^{d}$ is the impact ranking of the alternative Ai with regard to factor $\mathrm{Cj}$ assessed through the dth specialist and $\tilde{x}_{i j}^{d}=\left(l_{i j}^{d}, m i_{i j}^{d}, u_{i j}^{d}\right)$.

The subsequent step is to normalize the obtained value by implementing Eq. (19).

$\tilde{P}=\left[\tilde{p}_{i j}\right]_{m \times n}$ 
Table 3: Corresponding linguistic numbers

\begin{tabular}{ll}
\hline Linguistic factor & TFN \\
\hline (Very poor) & {$[0,1,3]$} \\
(Poor) & {$[1,3,5]$} \\
(Fair ) & {$[3,5,7]$} \\
(Good) & {$[5,7,9]$} \\
(Very good) & {$[7,9,10]$} \\
\hline
\end{tabular}

Thereafter, the normalization procedure is accomplished with the help of Eq. (20).

$\tilde{p}_{i j}=\left(\frac{l_{i j}}{u_{j}^{+}}, \frac{m i_{i j}}{u_{j}^{+}}, \frac{u_{i j}}{u_{j}^{+}}\right), \quad u_{j}^{+}=\max \left\{u_{i j}, i=1,2,3, \ldots, n\right\}$

Otherwise, we can also establish the preeminent anticipated level $u_{j}^{+}$and $j=1,2, \ldots, n$ is equivalent to one; otherwise zero. The standardized $\tilde{p}_{i j}$ value remains the same as before. In the next step, the experts need to again normalize values generated from the previous step by using Eq. (21).

$\tilde{Q}=\left[\tilde{q}_{i j}\right]_{m \times n} \quad i=1,2, \ldots, m ; \quad j=1,2,3, \ldots, n$

where, $\tilde{q}_{i j}=\tilde{p}_{i j} \otimes \tilde{w}_{i j}$ and after that, describe the Fuzzy Positive-Ideal Solution (FPIS) as well as Fuzzy Negative-Ideal Solution (FNIS). Further, to calculate their values, Eqs. (22)-(23) are used.

$A^{+}=\left(\tilde{q}_{1, \ldots}^{*} \ldots \tilde{q}_{j, \ldots}^{*} \ldots \tilde{q}_{n,}^{*}\right)$

$A^{-}=\left(\tilde{q}_{1, \ldots}^{*} \ldots \tilde{q}_{j, \ldots}^{*} \ldots \tilde{q}_{n,}^{*}\right)$

where, $\tilde{q}_{1}^{*}=(1,1,1) \otimes \tilde{w}_{i j}=\left(L w_{j}, M w_{j}, H w_{j}\right)$ and $\tilde{q}_{i j}^{-}=(0,0,0), j=1,2,3, \ldots, n$ for evaluating the range of every social factor/alternative affected by COVID-19 from the FPIS and FNIS. The distances $\left(\tilde{d}_{i}^{+}\right.$and $\left.\tilde{d}_{i}^{-}\right)$of every alternative from $\mathrm{A}+$ and $\mathrm{A}-$ can be assessed by using the area recompense method as presented in Eqs. (24)-(25).

$\tilde{d}_{i}^{+}=\sum_{j=1}^{n} d\left(\tilde{q}_{i j}, \tilde{q}_{i j}^{*}\right) \quad i=1,2, \ldots, m ; \quad j=1,2,3, \ldots, n$

$\tilde{d}_{i}^{-}=\sum_{j=1}^{n} d\left(\tilde{q}_{i j}, \tilde{q}_{i j}^{*}\right) \quad i=1,2, \ldots, m ; \quad j=1,2,3, \ldots, n$

Afterwards, the experts evaluate the value of gap in-between selected projects as alternatives. Chang et al. [26] described that $C \tilde{C}_{i}$ provides the most efficient and significant results for the 
calculation. When, $\tilde{d}_{i}^{+}$and $\tilde{d}_{i}^{-}$get evaluated, the gap value automatically generated in calculation is described in Eq. (26).

$C \tilde{C}_{i}=\frac{\tilde{k}_{i}^{-}}{\tilde{k}_{i}^{+}+\tilde{k}_{i}^{-}}=1-\frac{\tilde{k}_{i}^{+}}{\tilde{k}_{i}^{+}+k_{i}^{-}}, \quad i=1,2, \ldots, m$

where, $\frac{\tilde{k}_{i}^{-}}{\tilde{k}_{i}^{+}+\tilde{k}_{i}^{-}}$is the degree of satisfaction in the ith alternative affected by the pandemic, and $\frac{\tilde{k}_{i}^{+}}{\tilde{k}_{i}^{+}+\tilde{k}_{i}^{-}}$denotes the fuzzy gap in the ith alternative. This depends on the rank of a given alternative in the priority analysis.

\section{Empirical Analysis and Results}

Previous section described the theoretical description of adopted methodology. Furthermore, this section descriptively analyzes and gives real results obtained by applying the adopted methodology from previous section on the selected attributes of social factors in Saudi Arabia. With the help of Eqs. (1)-(10) and Tabs. 2, 4-7 show the fuzzy aggregated pair-wise matrixes for level 1, 2 and 3, respectively. With the help of Eqs. (11)-(17), Tabs. 8-11 show the defuzzified values of each group of matrix, consistency ratio and local weights. Further, Tab. 12 represents the global weights of the factors through the hierarchy.

For real time testing of the results, the authors have taken eight versions of healthcare application in this work. With the help of Eqs. (18)-(26) of fuzzy-TOPSIS method and Tabs. 3, 13-15 show the fuzzified ratings of the alternatives, normalized fuzzy-decision matrix and weighted normalized fuzzy-decision matrix, respectively. Further, Tab. 16 shows the satisfaction degree of each alternative. The results deliberated in Fig. 4 state that the results elicited through the adopted methodology are effective and appropriate for industry use.

Table 4: Fuzzy aggregated pair-wise matrix at level 1

\begin{tabular}{lll}
\hline & $(\mathrm{CT} 1)$ & $(\mathrm{CT} 2)$ \\
\hline (CT1) & $1,1,1$ & $0.312712,0.439525,0.625223$ \\
(CT2) & - & $1,1,1$
\end{tabular}

Table 5: Fuzzy aggregated pair-wise matrix at level 2 for early approach

\begin{tabular}{llll}
\hline & $(\mathrm{CT} 11)$ & (CT12) & $(\mathrm{CT} 13)$ \\
\hline (CT11) & $1,1,1$ & $0.258025,0.338652,0.505525$ & $0.360423,0.522012,0.807423$ \\
(CT12) & - & $1,1,1$ & $0.266527,0.365729,0.591139$ \\
(CT13) & - & - & $1,1,1$ \\
\hline
\end{tabular}


Table 6: Fuzzy aggregated pair-wise matrix at level 2 for late approach

\begin{tabular}{llll}
\hline & (CT21) & (CT22) & (CT23) \\
\hline (CT21) & $1,1,1$ & $0.366791,0.525111,0.965987$ & $0.226156,0.292857,0.416636$ \\
(CT22) & - & $1,1,1$ & $0.489625,0.637532,1.598658$ \\
(CT23) & - & - & $1,1,1$ \\
\hline
\end{tabular}

Table 7: Fuzzy aggregated pair-wise matrix at level 3 assessment

\begin{tabular}{llll}
\hline & $(\mathrm{CT} 231)$ & $(\mathrm{CT} 232)$ & (CT233) \\
\hline (CT231) & $1,1,1$ & $0.221525,0.287125,0.415256$ & $0.314678,0.461745,0.870545$ \\
(CT232) & - & $1,1,1$ & $0.244411,0.323858,0.480155$ \\
(CT233) & - & - & $1,1,1$ \\
\hline
\end{tabular}

Table 8: Defuzzified pair-wise matrix and local weights at level 1 for assessment

\begin{tabular}{llll}
\hline & (CT1) & (CT2) & Weights \\
\hline (CT1) & 1 & 0.454265 & 0.312260 \\
(CT2) & 2.201758 & 1 & 0.687640 \\
C.R. $=0.0005$ & & & \\
\hline
\end{tabular}

Table 9: Defuzzified pair-wise matrix and local weights at level 2 for CT1

\begin{tabular}{lllll}
\hline & $(\mathrm{CT} 11)$ & $(\mathrm{CT} 12)$ & (CT13) & Weights \\
\hline (CT11) & 1 & 0.360223 & 0.553026 & 0.178370 \\
(CT12) & 2.776225 & 1 & 0.397325 & 0.315480 \\
(CT13) & 1.808324 & 2.517023 & 1 & 0.506050 \\
CR $=0.01245$ & & & \\
\hline
\end{tabular}

Table 10: Defuzzified pair-wise matrix and local weights at level 2 for CT2

\begin{tabular}{lllll}
\hline & (CT21) & (CT22) & (CT23) & Weights \\
\hline (CT21) & 1 & 0.5957524 & 0.307156 & 0.172280 \\
(CT22) & 1.678786 & 1 & 0.691058 & 0.318870 \\
(CT23) & 3.256375 & 1.447245 & 1 & 0.508750 \\
CR $=0.00477$ & & & \\
\hline
\end{tabular}


Table 11: Defuzzified pair-wise matrix and local weights at level 2 for CT23

\begin{tabular}{lllll}
\hline & (CT231) & (CT232) & (CT233) & Weights \\
\hline (CT231) & 1 & 0.302775 & 0.526856 & 0.161670 \\
(CT232) & 3.30361 & 1 & 0.343056 & 0.310880 \\
(CT233) & 1.898389 & 2.915567 & 1 & 0.527350 \\
CR $=0.01402$ & & & \\
\hline
\end{tabular}

Table 12: Overall weights

\begin{tabular}{|c|c|c|c|c|c|c|c|}
\hline $\begin{array}{l}\text { 1st level } \\
\text { factors }\end{array}$ & $\begin{array}{l}\text { Local } \\
\text { weights at } \\
\text { 1st level }\end{array}$ & $\begin{array}{l}\text { 2nd level } \\
\text { factors }\end{array}$ & $\begin{array}{l}\text { Local } \\
\text { weights at } \\
\text { 2nd level }\end{array}$ & $\begin{array}{l}\text { Final } \\
\text { weights at } \\
\text { 2nd level }\end{array}$ & $\begin{array}{l}\text { 3rd level } \\
\text { factors }\end{array}$ & $\begin{array}{l}\text { Local } \\
\text { weights at } \\
\text { 3rd level }\end{array}$ & $\begin{array}{l}\text { Global } \\
\text { weights }\end{array}$ \\
\hline \multirow[t]{3}{*}{$\overline{\mathrm{CT} 1}$} & 0.312260 & CT11 & 0.178370 & 0.055697 & - & - & 0.055697 \\
\hline & & CT12 & 0.315480 & 0.098511 & - & - & 0.098511 \\
\hline & & CT13 & 0.506050 & 0.158010 & - & - & 0.158010 \\
\hline \multirow{5}{*}{$\mathrm{CT} 2$} & 0.687640 & CT21 & 0.172280 & 0.118460 & - & - & 0.118460 \\
\hline & & CT22 & 0.318870 & 0.219260 & - & - & 0.219260 \\
\hline & & CT23 & 0.508750 & 0.34983 & CT231 & 0.161670 & 0.056550 \\
\hline & & & & & СТ232 & 0.310880 & 0.108750 \\
\hline & & & & & CT233 & 0.527350 & 0.184480 \\
\hline
\end{tabular}

Table 13: Linguistic values of alternatives

\begin{tabular}{|c|c|c|c|c|c|c|c|c|}
\hline $\begin{array}{l}\text { Characteristics/ } \\
\text { alternatives }\end{array}$ & AE1 & AE2 & AE3 & AE4 & AE5 & AE6 & AE7 & AE8 \\
\hline CT11 & $\begin{array}{l}0.820000 \\
2.270000 \\
4.270000\end{array}$ & $\begin{array}{l}0.910000 \\
2.450000 \\
4.450000\end{array}$ & $\begin{array}{l}1.910000, \\
3.730000, \\
5.730000\end{array}$ & $\begin{array}{l}2.820000 \\
4.640000 \\
6.640000\end{array}$ & $\begin{array}{l}1.910000 \\
3.730000 \\
5.730000\end{array}$ & $\begin{array}{l}2.820000, \\
4.640000, \\
6.640000\end{array}$ & $\begin{array}{l}0.910000 \\
2.450000 \\
4.450000\end{array}$ & $\begin{array}{l}2.450000, \\
4.270000, \\
6.270000\end{array}$ \\
\hline CT12 & $\begin{array}{l}1.910000 \\
3.730000 \\
5.730000\end{array}$ & $\begin{array}{l}2.820000 \\
4.640000 \\
6.640000\end{array}$ & $\begin{array}{l}2.820000, \\
4.820000, \\
6.820000\end{array}$ & $\begin{array}{l}1.450000 \\
3.070000 \\
4.910000\end{array}$ & $\begin{array}{l}0.820000 \\
2.270000 \\
4.270000\end{array}$ & $\begin{array}{l}4.270000, \\
6.270000, \\
8.140000\end{array}$ & $\begin{array}{l}2.820000 \\
4.640000 \\
6.640000\end{array}$ & $\begin{array}{l}1.910000, \\
3.730000, \\
5.730000\end{array}$ \\
\hline CT13 & $\begin{array}{l}0.820000 \\
2.270000 \\
4.270000\end{array}$ & $\begin{array}{l}4.270000 \\
6.270000 \\
8.140000\end{array}$ & $\begin{array}{l}1.640000, \\
3.550000, \\
5.550000\end{array}$ & $\begin{array}{l}3.180000 \\
5.180000 \\
7.100000\end{array}$ & $\begin{array}{l}1.450000 \\
3.070000 \\
4.910000\end{array}$ & $\begin{array}{l}0.820000, \\
2.270000, \\
4.270000\end{array}$ & $\begin{array}{l}4.270000 \\
6.270000 \\
8.140000\end{array}$ & $\begin{array}{l}1.640000, \\
3.550000, \\
5.550000\end{array}$ \\
\hline СТ21 & $\begin{array}{l}1.910000 \\
3.730000 \\
5.730000\end{array}$ & $\begin{array}{l}2.820000 \\
4.640000 \\
6.640000\end{array}$ & $\begin{array}{l}1.910000, \\
3.730000, \\
5.730000\end{array}$ & $\begin{array}{l}2.090000 \\
3.730000 \\
5.730000\end{array}$ & $\begin{array}{l}2.820000 \\
4.640000 \\
6.640000\end{array}$ & $\begin{array}{l}1.910000, \\
3.730000, \\
5.730000\end{array}$ & $\begin{array}{l}2.820000 \\
4.640000 \\
6.640000\end{array}$ & $\begin{array}{l}1.910000, \\
3.730000, \\
5.730000\end{array}$ \\
\hline CT22 & $\begin{array}{l}4.270000 \\
6.270000 \\
8.140000\end{array}$ & $\begin{array}{l}1.640000 \\
3.550000 \\
5.550000\end{array}$ & $\begin{array}{l}2.820000, \\
4.640000, \\
6.640000\end{array}$ & $\begin{array}{l}1.910000 \\
3.730000 \\
5.730000\end{array}$ & $\begin{array}{l}2.820000 \\
4.640000 \\
6.640000\end{array}$ & $\begin{array}{l}1.910000, \\
3.730000, \\
5.730000\end{array}$ & $\begin{array}{l}2.090000 \\
3.730000 \\
5.730000\end{array}$ & $\begin{array}{l}2.820000, \\
4.640000, \\
6.640000\end{array}$ \\
\hline СТ231 & $\begin{array}{l}2.820000 \\
4.640000 \\
6.640000\end{array}$ & $\begin{array}{l}1.910000 \\
3.730000 \\
5.730000\end{array}$ & $\begin{array}{l}2.450000, \\
4.270000, \\
6.270000\end{array}$ & $\begin{array}{l}1.450000 \\
3.070000 \\
4.910000\end{array}$ & $\begin{array}{l}0.820000 \\
2.270000 \\
4.270000\end{array}$ & $\begin{array}{l}0.910000, \\
2.450000, \\
4.450000\end{array}$ & $\begin{array}{l}1.550000 \\
3.180000 \\
5.180000\end{array}$ & $\begin{array}{l}1.450000, \\
3.180000, \\
5.180000\end{array}$ \\
\hline СТ232 & $\begin{array}{l}0.820000 \\
2.270000 \\
4.270000\end{array}$ & $\begin{array}{l}0.910000 \\
2.450000 \\
4.450000\end{array}$ & $\begin{array}{l}1.910000 \\
3.730000 \\
5.730000\end{array}$ & $\begin{array}{l}2.820000 \\
4.640000 \\
6.640000\end{array}$ & $\begin{array}{l}1.910000 \\
3.730000 \\
5.730000\end{array}$ & $\begin{array}{l}2.820000, \\
4.640000 \\
6.640000\end{array}$ & $\begin{array}{l}0.910000 \\
2.450000 \\
4.450000\end{array}$ & $\begin{array}{l}2.450000, \\
4.270000, \\
6.270000\end{array}$ \\
\hline СТ233 & $\begin{array}{l}1.910000 \\
3.730000 \\
5.730000\end{array}$ & $\begin{array}{l}2.820000 \\
4.640000 \\
6.640000\end{array}$ & $\begin{array}{l}2.820000, \\
4.820000, \\
6.820000\end{array}$ & $\begin{array}{l}\text { 1.450000, } \\
3.070000, \\
4.910000\end{array}$ & $\begin{array}{l}0.820000 \\
2.270000 \\
4.270000\end{array}$ & $\begin{array}{l}4.270000, \\
6.270000, \\
8.140000\end{array}$ & $\begin{array}{l}2.820000 \\
4.640000 \\
6.640000\end{array}$ & $\begin{array}{l}1.910000, \\
3.730000, \\
5.730000\end{array}$ \\
\hline
\end{tabular}


Table 14: Normalized fuzzy-decision matrix

\begin{tabular}{|c|c|c|c|c|c|c|c|c|}
\hline $\begin{array}{l}\text { Characteristics/ } \\
\text { alternatives }\end{array}$ & AE1 & AE2 & AE3 & AE4 & AE5 & AE6 & AE7 & AE8 \\
\hline CT11 & $\begin{array}{l}0.420000, \\
0.690000, \\
1.000000\end{array}$ & $\begin{array}{l}0.390000, \\
0.700000, \\
1.000000\end{array}$ & $\begin{array}{l}0.468200 \\
0.687500 \\
0.892500\end{array}$ & $\begin{array}{l}0.469200, \\
0.698400, \\
0.917700\end{array}$ & $\begin{array}{l}0.158900, \\
0.337700, \\
0.538300\end{array}$ & $\begin{array}{l}0.270000 \\
0.560000 \\
0.860000\end{array}$ & $\begin{array}{l}0.250000, \\
0.550000, \\
0.860000\end{array}$ & $\begin{array}{l}0.394900, \\
0.649800, \\
0.929900\end{array}$ \\
\hline CT12 & $\begin{array}{l}0.469200 \\
0.698400 \\
0.917700\end{array}$ & $\begin{array}{l}0.158900, \\
0.337700, \\
0.538300\end{array}$ & $\begin{array}{l}0.587700 \\
0.807000 \\
1.000000\end{array}$ & $\begin{array}{l}0.210000 \\
0.460000 \\
0.730000\end{array}$ & $\begin{array}{l}0.120000, \\
0.350000, \\
0.660000\end{array}$ & $\begin{array}{l}0.230000, \\
0.470000 \\
0.780000\end{array}$ & $\begin{array}{l}0.220000 \\
0.490000 \\
0.800000\end{array}$ & $\begin{array}{l}0.420100, \\
0.700200 \\
1.000000\end{array}$ \\
\hline CT13 & $\begin{array}{l}0.468200, \\
0.687500, \\
0.892500\end{array}$ & $\begin{array}{l}0.394900, \\
0.649800, \\
0.929900\end{array}$ & $\begin{array}{l}0.460000 \\
0.690000 \\
0.910000\end{array}$ & $\begin{array}{l}0.468200, \\
0.687500, \\
0.892500\end{array}$ & $\begin{array}{l}0.394900, \\
0.649800, \\
0.929900\end{array}$ & $\begin{array}{l}0.420000, \\
0.690000 \\
1.000000\end{array}$ & $\begin{array}{l}0.390000 \\
0.700000 \\
1.000000\end{array}$ & $\begin{array}{l}0.320000 \\
0.580000 \\
0.850000\end{array}$ \\
\hline СТ21 & $\begin{array}{l}0.468200 \\
0.687500 \\
0.892500\end{array}$ & $\begin{array}{l}0.394900, \\
0.649800, \\
0.929900\end{array}$ & $\begin{array}{l}0.460000 \\
0.690000 \\
0.910000\end{array}$ & $\begin{array}{l}0.587700 \\
0.807000 \\
1.000000\end{array}$ & $\begin{array}{l}0.420100, \\
0.700200, \\
1.000000\end{array}$ & $\begin{array}{l}0.469200 \\
0.698400 \\
0.917700\end{array}$ & $\begin{array}{l}0.158900, \\
0.337700, \\
0.538300\end{array}$ & $\begin{array}{l}0.320000 \\
0.580000 \\
0.850000\end{array}$ \\
\hline $\mathrm{CT}_{2}^{2}$ & $\begin{array}{l}0.587700 \\
0.807000 \\
1.000000\end{array}$ & $\begin{array}{l}0.420100, \\
0.700200, \\
1.000000\end{array}$ & $\begin{array}{l}0.460000 \\
0.680000 \\
0.890000\end{array}$ & $\begin{array}{l}0.460000 \\
0.690000 \\
0.910000\end{array}$ & $\begin{array}{l}0.320000, \\
0.580000, \\
0.850000\end{array}$ & $\begin{array}{l}0.468200 \\
0.687500 \\
0.892500\end{array}$ & $\begin{array}{l}0.394900, \\
0.649800, \\
0.929900\end{array}$ & $\begin{array}{l}0.370000, \\
0.630000, \\
0.900000\end{array}$ \\
\hline $\mathrm{CT}_{2}^{2}$ & $\begin{array}{l}0.270000 \\
0.560000 \\
0.860000\end{array}$ & $\begin{array}{l}0.250000 \text {, } \\
0.550000 \text {, } \\
0.860000\end{array}$ & $\begin{array}{l}0.469200, \\
0.698400, \\
0.917700\end{array}$ & $\begin{array}{l}0.158900 \\
0.337700 \\
0.538300\end{array}$ & $\begin{array}{l}0.270000 \text {, } \\
0.560000 \text {, } \\
0.860000\end{array}$ & $\begin{array}{l}0.250000, \\
0.550000 \\
0.860000\end{array}$ & $\begin{array}{l}0.469200 \\
0.698400 \\
0.917700\end{array}$ & $\begin{array}{l}0.158900, \\
0.337700, \\
0.538300\end{array}$ \\
\hline CT232 & $\begin{array}{l}0.230000 \\
0.470000 \\
0.780000\end{array}$ & $\begin{array}{l}0.220000 \text {, } \\
0.490000 \text {, } \\
0.800000\end{array}$ & $\begin{array}{l}0.210000 \text {, } \\
0.460000, \\
0.730000\end{array}$ & $\begin{array}{l}0.120000 \\
0.350000 \\
0.660000\end{array}$ & $\begin{array}{l}0.230000 \text {, } \\
0.470000 \text {, } \\
0.780000\end{array}$ & $\begin{array}{l}0.220000 \text {, } \\
0.490000 \text {, } \\
0.800000\end{array}$ & $\begin{array}{l}0.210000 \\
0.460000 \\
0.730000\end{array}$ & $\begin{array}{l}0.120000, \\
0.350000, \\
0.660000\end{array}$ \\
\hline CT233 & $\begin{array}{l}0.420000 \\
0.690000 \\
1.000000\end{array}$ & $\begin{array}{l}0.390000, \\
0.700000, \\
1.000000\end{array}$ & $\begin{array}{l}0.468200, \\
0.687500, \\
0.892500\end{array}$ & $\begin{array}{l}0.394900, \\
0.649800, \\
0.929900\end{array}$ & $\begin{array}{l}0.420000, \\
0.690000, \\
1.000000\end{array}$ & $\begin{array}{l}0.390000, \\
0.700000 \\
1.000000\end{array}$ & $\begin{array}{l}0.468200, \\
0.687500, \\
0.892500\end{array}$ & $\begin{array}{l}0.394900, \\
0.649800, \\
0.929900\end{array}$ \\
\hline
\end{tabular}

\section{Validation of Results}

\subsection{Sensitivity Analysis}

Identifying the quality and robustness of extracted results is very important and crucial task in any type of experimental outcome [27,28]. To conduct this type of robustness assurance in this proposed paper, the authors performed a sensitivity analysis that validated the effectivity of the evaluated results in terms of numerical value. Further, to evaluate the sensitivity in this paper, the authors again performed the experiment with ten experiments by slightly increasing or decreasing the weight value for specific factor at a specific time. This type of evaluation gives an ideal understanding about the sustainability of evaluated results. A numeric result evaluation for sensitivity analysis is shown in Tab. 17.

\subsection{Comparison}

To make the evaluated results more reliable and effective, the authors performed another result verification approach through comparison analysis. To conduct this analysis approach, the authors performed the same evaluation with different MCDM approaches like: ClassicalAHP-TOPSIS [15], Fuzzy-AHP-SAM [17], Delphi-AHP-TOPSIS [19] and Fuzzy-Delphi-AHPTOPSIS [25]. This type o analysis and its results gives a brief idea about the effectiveness of results and its adopted methodology. This strategy also establishes credibility for the derived 
results [29]. The results discussed in Tab. 18 tell demonstrate fuzzy based approaches provide better results in comparison of other techniques.

Table 15: Weighted normalized fuzzy-decision matrix

\begin{tabular}{lllllllll}
\hline $\begin{array}{l}\text { Characteristics/ } \\
\text { alternatives }\end{array}$ & AE1 & AE2 & AE3 & AE4 & AE5 & AE6 & AE7 & AE8 \\
\hline CT11 & 0.158600 & 0.083300 & 0.099400 & 0.083300 & 0.158600 & 0.083300 & 0.158600 & 0.083300 \\
& 0.266700 & 0.179000 & 0.198500 & 0.179000 & 0.266700 & 0.179000 & 0.266700 & 0.179000 \\
CT12 & 0.369400 & 0.286700 & 0.310900 & 0.286700 & 0.369400 & 0.286700 & 0.369400 & 0.286700 \\
& 0.049300 & 0.127000 & 0.006400 & 0.006600 & 0.004700 & 0.006600 & 0.004700 & 0.006600 \\
& 0.107300 & 0.242500 & 0.010900 & 0.010900 & 0.008400 & 0.010900 & 0.008400 & 0.010900 \\
CT13 & 0.193900 & 0.369400 & 0.015200 & 0.015200 & 0.012400 & 0.015200 & 0.012400 & 0.015200 \\
& 0.002700 & 0.000200 & 0.048100 & 0.050600 & 0.072700 & 0.050600 & 0.072700 & 0.050600 \\
& 0.007500 & 0.000500 & 0.098100 & 0.099600 & 0.118100 & 0.099600 & 0.118100 & 0.099600 \\
CT21 & 0.015300 & 0.001600 & 0.172600 & 0.172600 & 0.193900 & 0.172600 & 0.193900 & 0.172600 \\
& 0.037500 & 0.008000 & 0.002200 & 0.001500 & 0.005900 & 0.001500 & 0.005900 & 0.001500 \\
& 0.078300 & 0.017400 & 0.006900 & 0.005600 & 0.013200 & 0.005600 & 0.013200 & 0.005600 \\
CT22 & 0.154400 & 0.037200 & 0.015000 & 0.013300 & 0.023400 & 0.013300 & 0.023400 & 0.013300 \\
& 0.127000 & 0.002000 & 0.010400 & 0.022900 & 0.032900 & 0.022900 & 0.032900 & 0.022900 \\
& 0.242500 & 0.004000 & 0.036700 & 0.056800 & 0.068700 & 0.056800 & 0.068700 & 0.056800 \\
CT231 & 0.369400 & 0.009400 & 0.095200 & 0.120300 & 0.135400 & 0.120300 & 0.135400 & 0.120300 \\
& 0.004700 & 0.006600 & 0.099400 & 0.083300 & 0.158600 & 0.083300 & 0.158600 & 0.083300 \\
& 0.008400 & 0.010900 & 0.198500 & 0.179000 & 0.266700 & 0.179000 & 0.266700 & 0.179000 \\
CT232 & 0.012400 & 0.015200 & 0.310900 & 0.286700 & 0.369400 & 0.286700 & 0.369400 & 0.286700 \\
& 0.072700 & 0.050600 & 0.072700 & 0.050600 & 0.072700 & 0.053100 & 0.049300 & 0.127000 \\
& 0.118100 & 0.099600 & 0.118100 & 0.099600 & 0.118100 & 0.105800 & 0.107300 & 0.242500 \\
CT233 & 0.193900 & 0.172600 & 0.193900 & 0.172600 & 0.193900 & 0.193900 & 0.193900 & 0.369400 \\
& 0.005900 & 0.001500 & 0.005900 & 0.001500 & 0.005900 & 0.007800 & 0.002700 & 0.000200 \\
& 0.013200 & 0.005600 & 0.013200 & 0.005600 & 0.013200 & 0.015600 & 0.007500 & 0.000500 \\
& 0.023400 & 0.013300 & 0.023400 & 0.013300 & 0.023400 & 0.026100 & 0.015300 & 0.001600 \\
\hline
\end{tabular}

Table 16: Closeness coefficients of the various alternatives

\begin{tabular}{lllll}
\hline Alternatives (AE) & $\mathrm{di}+$ & $\mathrm{di}-$ & Degree gap CCi+ & Satisfaction degree \\
\hline AE1 & 0.812457 & 0.144567 & 0.147556 & 0.852256 \\
AE2 & 0.778645 & 0.185895 & 0.188445 & 0.811852 \\
AE3 & 0.924578 & 0.045865 & 0.041487 & 0.963957 \\
AE4 & 0.914675 & 0.045878 & 0.031785 & 0.979654 \\
AE5 & 0.714576 & 0.246598 & 0.255225 & 0.721985 \\
AE6 & 0.934658 & 0.075568 & 0.072358 & 0.936854 \\
AE7 & 0.924579 & 0.058895 & 0.051856 & 0.944256 \\
AE8 & 0.956457 & 0.055562 & 0.051965 & 0.956365 \\
\hline
\end{tabular}




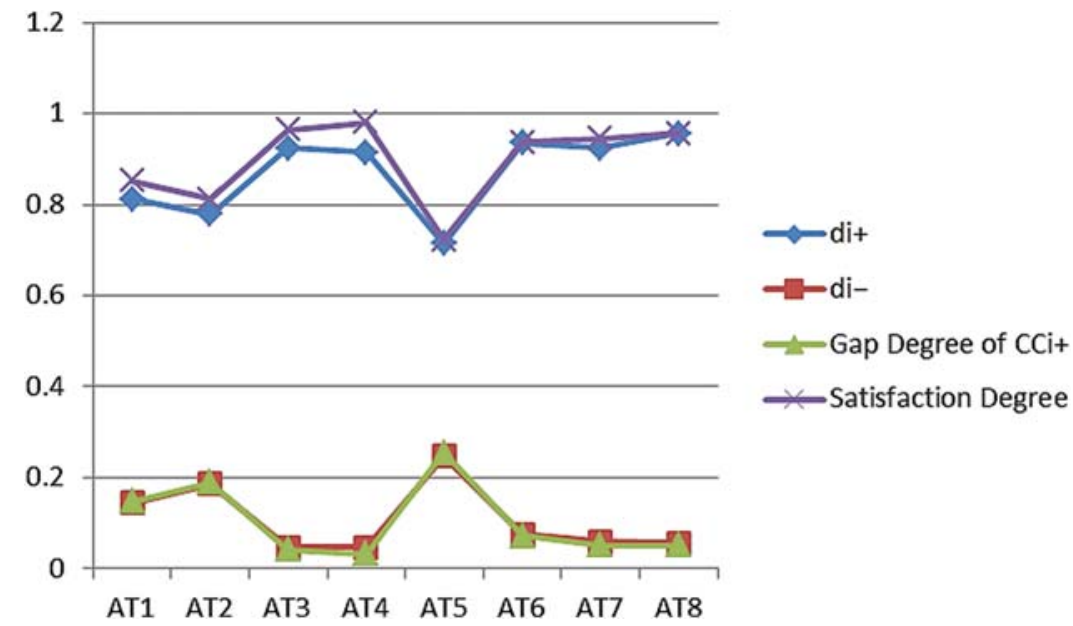

Figure 4: Statistical outcomes of various alternatives

Table 17: Sensitivity analysis

\begin{tabular}{llllllllll}
\hline Experiments & $\begin{array}{l}\text { Weights/ } \\
\text { alternatives }\end{array}$ & AE1 & AE2 & AE3 & AE4 & AE5 & AE6 & AE7 & AE8 \\
\hline E0 & $\begin{array}{l}\text { Original } \\
\text { weights }\end{array}$ & 0.852256 & 0.811852 & 0.963957 & 0.979654 & 0.721985 & 0.936854 & 0.944256 & 0.956365 \\
& CT11 & 0.867256 & 0.825152 & 0.977457 & 0.989754 & 0.734485 & 0.934354 & 0.948756 & 0.976265 \\
E1 & CT12 & 0.865556 & 0.731052 & 0.888157 & 1.013654 & 0.743785 & 0.893254 & 0.885356 & 0.961865 \\
E2 & CT13 & 0.760756 & 0.813052 & 0.956757 & 0.965054 & 0.717185 & 0.890354 & 0.918056 & 0.872465 \\
E3 & CT21 & 0.940556 & 0.905952 & 1.064757 & 0.982154 & 0.722385 & 1.070054 & 1.059956 & 1.039465 \\
E4 & CT22 & 0.789156 & 0.758052 & 0.924857 & 0.946354 & 0.760085 & 0.869254 & 0.872656 & 0.920765 \\
E5 & CT231 & 0.894556 & 0.847152 & 0.987457 & 0.998654 & 0.666585 & 0.967154 & 0.989156 & 0.985065 \\
E6 & CT232 & 0.822356 & 0.789252 & 0.930857 & 0.946954 & 0.689385 & 0.930254 & 0.924456 & 0.910365 \\
E7 & CT233 & 0.897656 & 0.828152 & 0.983057 & 0.992454 & 0.748685 & 0.938454 & 0.958356 & 0.995465 \\
E8 & & & & & & & & &
\end{tabular}

Table 18: Comparison of the results from different methods

\begin{tabular}{lllllllll}
\hline Approaches/alternatives & AE1 & AE2 & AE3 & AE4 & AE5 & AE6 & AE7 & AE8 \\
\hline Fuzzy-AHP-TOPSIS & 0.852256 & 0.811852 & 0.963957 & 0.979654 & 0.721985 & 0.936854 & 0.944256 & 0.956365 \\
Classical-AHP-TOPSIS & 0.846656 & 0.810952 & 0.967557 & 0.979954 & 0.722885 & 0.937754 & 0.948456 & 0.967265 \\
Fuzzy-AHP-SAM & 0.862256 & 0.812152 & 0.965657 & 0.977854 & 0.722585 & 0.936854 & 0.941156 & 0.955065 \\
Delphi-AHP-TOPSIS & 0.847656 & 0.812442 & 0.962417 & 0.981464 & 0.721345 & 0.936944 & 0.947376 & 0.957695 \\
Fuzzy-Delphi-AHP-TOPSIS & 0.853556 & 0.808962 & 0.962197 & 0.978644 & 0.721525 & 0.936264 & 0.940736 & 0.956035 \\
\hline
\end{tabular}

\section{Discussion}

As evident by the findings of our study, this pandemic has had a huge adverse effect on the social life of people and severely impacted other indices of human activity. The results of this proposed paper show that the most critical and challenged social factor in Saudi Arabia during the pandemic is the country's economy. Hence, the country needs to recalibrate its strategies to combat the financial crunch. The positive trend in this context indicates that media in Saudi Arabia is proactively disseminating the information regarding all the health advisories and policies issues 
by the government. Preventive measures like the strict rules and regulations of travel bans and lockdowns also show the willingness of the government to neutralise the adverse effect of the pandemic in country. This crisis also demands advanced technical equipments and technologies to predict, trace and identify the possible sectors that need extra stimulus in terms of resources to overcome the setbacks caused by the pandemic. In this row, as per the findings of our study, some other challenging sectors that need government's intervention are: Work, Education, Relationship, Gathering, Psychological, Emotional and Religion.

Tackling the situation of financial emergency in Saudi Arabia so as to restore the financial security of the citizens emerges as a major challenge for the country's administrators in the present context. The results of this study show that the lowest earning person has more faith in the government and a greater measure of social trust than the ones in the higher income brackets. Hence, this situation demands a redevelopment of infrastructure in a manner where the initiatives taken by the government percolate to the citizens in the low income groups and that too expeditiously. The pandemic forced many individuals into a life of unpredictability; people were left to struggle for fulfilling their basic requirements, especially food and medicines. The proposed machine learning approach needs to be applied at the early stages of such crisis situations as an effective identification mechanism to prevent the transmission and spread of the disease. However, along with preventive measures, there is also an imminent need to create social awareness and condition people's attitudes for better preparedness to fight with the ills of the pandemic. Media can play a vital role in achieving this attitudinal change in Saudi Arabia. There is an immense need to motivate the citizens to abide by restrictions while citing out the benefits of doing so. Further, media also needs to redefine the social factors for country and discuss the possible growth in country after or during this harsh time period.

\section{Conclusion}

The entire global society is now suffering from the after-effects of Coronavirus. Further, the fight with COVID-19 pandemic needs collective and collaborative participation. In this league, the experts can also contribute significantly by analyzing the societal impact of this pandemic in their country or locality from various point of views. The proposed Machine Learning framework will prove to be a credible, effective and prompt mechanism for evaluating the impact of the pandemic in Saudi Arabia. However, the framework could also be employed in any other similar analyses for eliciting accurate findings. Thus, similar research work must be carried out at all periods with the intention of tracking changes, and should be submitted to assist officials in updating their proposals and policies.

Acknowledgement: This research work was funded by Institutional Fund Projects under grant no. (IFPHI-267-611-2020). Therefore, authors gratefully acknowledge technical and financial support from the Ministry of Education and King Abdulaziz University, DSR, Jeddah, Saudi Arabia.

Funding Statement: Funding for this study was received from the Ministry of Education and Deanship of Scientific Research at King Abdulaziz University, Kingdom of Saudi Arabia under the Grant No. IFPHI-267-611-2020.

Conflicts of Interest: The authors declare that they have no conflicts of interest to report regarding the present study. 


\section{References}

[1] K. Chakraborty and P. Maity, "COVID-19 outbreak: Migration, effects on society, global environment and prevention," Science of the Total Environment, vol. 5, no. 6, pp. 1388-1396, 2020.

[2] Towards a Research Roadmap, COVID 19 Public Health Emergency of International Concern (PHEIC) Global Research and Innovation Forum. Geneva, Switzerland: World Health Organization, 2020. [Online]. Available: https://www.who.int/publications/m/item/covid-19-public-health-emergency-of-internationalconcern-(pheic)-global-research-and-innovation-forum.

[3] B. McKay, J. Calfas and T. Ansari, "Coronavirus declared pandemic by world health organization," Wall Street Journal, vol. 5, no. 6, pp. 1-7, 2020.

[4] J. Elflein, COVID-19 Cases and Deaths Statistics by Country. Hamburg, Germany: Statista, pp. 1-15, 2020. [Online]. Available: https://www.statista.com/statistics/1105264/coronavirus-covid-19-cases-mostaffected-countries-worldwide/.

[5] J. Singh and J. Singh, "COVID-19 and its impact on society," Electronic Research Journal of Social Sciences and Humanities, vol. 2, no. 1, pp. 103-106, 2020.

[6] E. Dong, H. Du and L. Gardner, "An interactive web-based dashboard to track COVID-19 in real time," Lancet Infectious Diseases, vol. 20, no. 5, pp. 533-534, 2020.

[7] A. Attaallah, M. Ahmad, A. H. Seh, A. Agrawal, R. Kumar et al., "Estimating the impact of COVID-19 pandemic on the research community in the Kingdom of Saudi Arabia," Computer Modeling in Engineering \& Sciences, vol. 126, no. 1, pp. 419-436, 2021.

[8] M. T. J. Ansari, F. A. Alzahrani, D. Pandey and A. Agrawal, "A fuzzy TOPSIS based analysis toward selection of effective security requirements engineering approach for trustworthy healthcare software development," BMC Medical Informatics and Decision Making, vol. 20, no. 1, pp. 1-13, 2020.

[9] P. Majumder, P. Biswas and S. Majumder, "Application of new TOPSIS approach to identify the most significant risk factor and continuous monitoring of death of COVID-19," Electron Journal of General Medicine, vol. 17, no. 6, pp. 1-12, 2020.

[10] Z. Yang, X. Li, H. Garg and M. Qi, "Decision support algorithm for selecting an antivirus mask over COVID-19 pandemic under spherical normal fuzzy environment," International Journal of Environmental Research and Public Health, vol. 17, no. 10, pp. 1-27, 2020.

[11] Z. Hashemkhani, M. Yazdani, E. Torkayeshand and A. Derakhti, "Application of a gray-based decision support framework for location selection of a temporary hospital during COVID-19 pandemic," Symmetry, vol. 12, no. 6, pp. 886-892, 2020.

[12] M. A. Mohammed, H. K. Abdulkareem, A. S. Alwaisy, S. A. Mostafa, S. Al-Fahdawi et al., "Benchmarking methodology for selection of optimal COVID-19 diagnostic model based on entropy and TOPSIS methods," IEEE Access, vol. 8, no. 8, pp. 99115-99131, 2020.

[13] King Abdullah Petroleum Studies and Research Center, Saudi Arabia Coronavirus Disease (COVID-19) Situation. Riyadh, Saudi Arabia: Ministry of Health, 2021. [Online]. Available: https://datasource.kapsarc.org/explore/dataset/saudi-arabia-coronavirus-disease-covid-19-situation.

[14] R. Kumar, M. Alenezi, M. T. J. Ansari, B. K. Gupta, A. Agrawal et al., "Evaluating the impact of malware analysis techniques for securing web applications through a decision-making framework under fuzzy environment," International Journal of Intelligent Engineering and Systems, vol. 13, no. 6, pp. 94 109, 2020.

[15] A. Ahmad, K. M. Alkharfy, Z. Alrabiah and A. Alhossan, "Saudi Arabia, pharmacists and COVID-19 pandemic," Journal of Pharmaceutical Policy and Practice, vol. 13, no. 1, pp. 1-3, 2020.

[16] Kingdom's Government Sets Preventive, Precautionary Measures to Prevent COVID-19 Infection Transmission, Interior Ministry Says. Riyadh, Saudi Arabia: Saudi Press Agency, 2021. [Online]. Available: https://www.spa.gov.sa/viewstory.php?lang=en\&newsid=2043855.

[17] D. Trehan, Detecting COVID-19 using Deep Learning. CL, USA: Towards Data Science, 2020. [Online]. Available: https://towardsdatascience.com/detecting-covid-19-using-deep-learning-262956b6f981.

[18] T. L. Satty, "The analytic hierarchy process," Analytic Hierarchy Process Journal, vol. 5, no. 6, pp. 187194, 1980. 
[19] C. S. Yu, "A GP-AHP method for solving group decision-making fuzzy AHP problems," Computers \& Operations Research, vol. 29, no. 14, pp. 1969-2001, 2020.

[20] G. S. Liang and M. J. J. Wang, "Personnel selection using fuzzy MCDM algorithm," European Journal of Operational Research, vol. 78, no. 1, pp. 22-33, 2020.

[21] A. H. Lee, W. C. Chen and C. J. Chang, "A fuzzy AHP and BSC approach for evaluating performance of IT department in the manufacturing industry in Taiwan," Expert Systems with Applications, vol. 34, no. 1, pp. 96-107, 2008.

[22] A. Algarni, M. Ahmad, A. Attaallah, A. Agrawal, R. Kumar et al., "A fuzzy multi-objective coveringbased security quantification model for mitigating risk of web based medical image processing system," International Journal of Advanced Computer Science and Applications, vol. 11, no. 1, pp. 481-489, 2020.

[23] A. Ishizaka and P. Nemery, Multi-Criteria Decision Analysis: Methods and Software. NJ, USA: John Wiley \& Sons, 2013. [Online]. Available: https://www.wiley.com/en-in/Multi+criteria+Decision+Analysis: +Methods+and+Software-p-9781118644911.

[24] S. J. Chen and C. L. Hwang, Fuzzy Multiple Attribute Decision Making Methods. Berlin, Heidelberg: Springer, 1992. [Online]. Available: https://www.springer.com/gp/book/9783540549987.

[25] C. L. Hwang and K. Yoon, "Methods for multiple attribute decision making," Lecture Notes in Economics and Mathematical Systems, vol. 186, pp. 58-191, 1981.

[26] C. W. Chang, C. R. Wu and H. L. Lin, "Integrating fuzzy theory and hierarchy concepts to evaluate software quality," Software Quality Journal, vol. 16, no. 2, pp. 263-276, 2008.

[27] R. Kumar, M. Zarour, M. Alenezi, A. Agrawal and R. A. Khan, "Measuring security durability of software through fuzzy-based decision-making process," International Journal of Computational Intelligence Systems, vol. 12, no. 2, pp. 627-642, 2019.

[28] C. Rorres, M. Romano, J. A. Miller, J. M. Mossey, T. H. Grubesic et al., "Contact tracing for the control of infectious disease epidemics: Chronic wasting disease in deer farms," Epidemics, vol. 23, no. 5, pp. 71-75, 2018.

[29] V. K. R. Chimmula and L. Zhang, "Time series forecasting of COVID-19 transmission in Canada using LSTM Networks,” Chaos Solitons, and Fractals, vol. 135, no. 8, pp. 109864, 2019. 